\title{
Robert's uterus: a rare congenital müllerian duct anomaly causing haematometra
}

\author{
Satish Babu Maddukuri, ${ }^{1}$ Lakshmikanth Halegubbi Karegowda, ${ }^{2}$ \\ Koteshwara Prakashini, ${ }^{3}$ Swarna Kantipudi ${ }^{3}$
}

${ }^{1}$ Department of

Radiodiagnosis, Kasturba Medical College, Manipal, Karnataka, India

${ }^{2}$ Department of Radiology, Kasturba Medical College, Manipal, Karnataka, India ${ }^{3}$ Department of Radiology and Imaging, Kasturba Medical College, Manipal, Karnataka, India

\section{Correspondence to} Dr Satish Babu Maddukuri, msatishbabu981@gmail.com

Accepted 5 October 2014
CrossMark

To cite: Maddukuri SB, Karegowda LH, Prakashini K, et al. BMJ Case Rep Published online: [please include Day Month Year] doi:10.1136/bcr-2014204489

\section{DESCRIPTION}

A 16-year-old girl presented with severe cyclical lower abdominal pain during menstruation, associated with vomiting, since 1year. Her menstrual cycles were regular: 3/30. Transabdominal ultrasound showed echogenic fluid collection in the endometrial cavity of the uterus, suggesting haematometra. A septated left adnexal cyst with echogenic fluid was seen, suggestive of hematosalpinx or endometriotic cyst.

Suspecting a müllerian duct anomaly (MDA), a plain MRI study of the pelvis was performed with the following sequences: T2-weighted (T2W) images in coronal, axial and sagittal planes, T1W axial and T2 FS coronal images.

Coronal T2W images showed thick hypointense septum in the uterus, which was asymmetrically dividing the endometrial cavity into a smaller right cavity and a larger left cavity. The lower portion of the septum was transversely oriented (figure 1 ) and was obstructing the left endometrial cavity leading to its distension and haematometra (figure 2).

Dilation of the left fallopian tube was also seen, which was filled with haemorrhagic fluid,

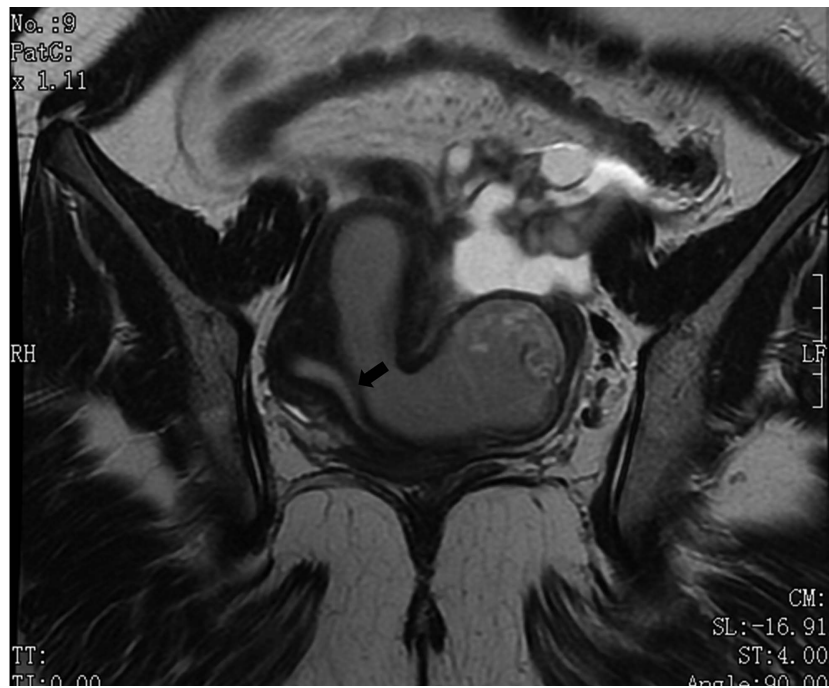

Figure 1 Coronal T2-weighted MRI showing a well-defined hypointense septum dividing the endometrial cavity. The lower portion of the septum was transversely oriented and obstructing the left endometrial cavity, which was distended with haemorrhagic fluid. The right endometrial cavity was communicating with the cervical canal. Uterine fundus contour was normal.

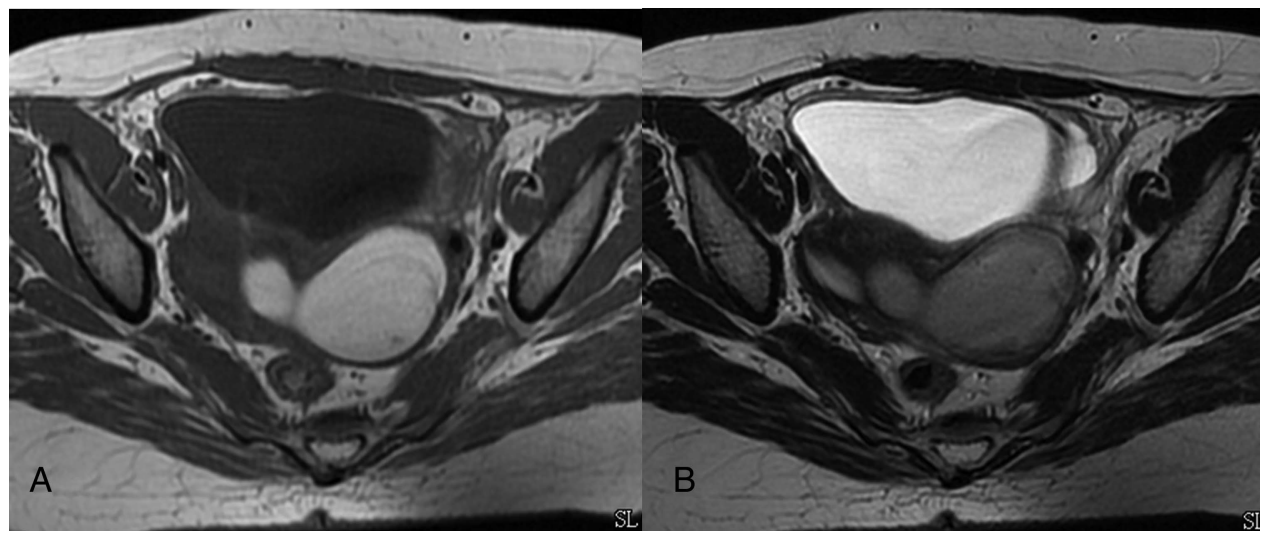

Figure 2 Axial T1-weighted (T1W) (A) and T2W (B) MRI showing the T1 hyper intense fluid in the left endometrial cavity, suggesting haematometra. Hypointense septum separating the two cavities was well visualised on T2W image. 


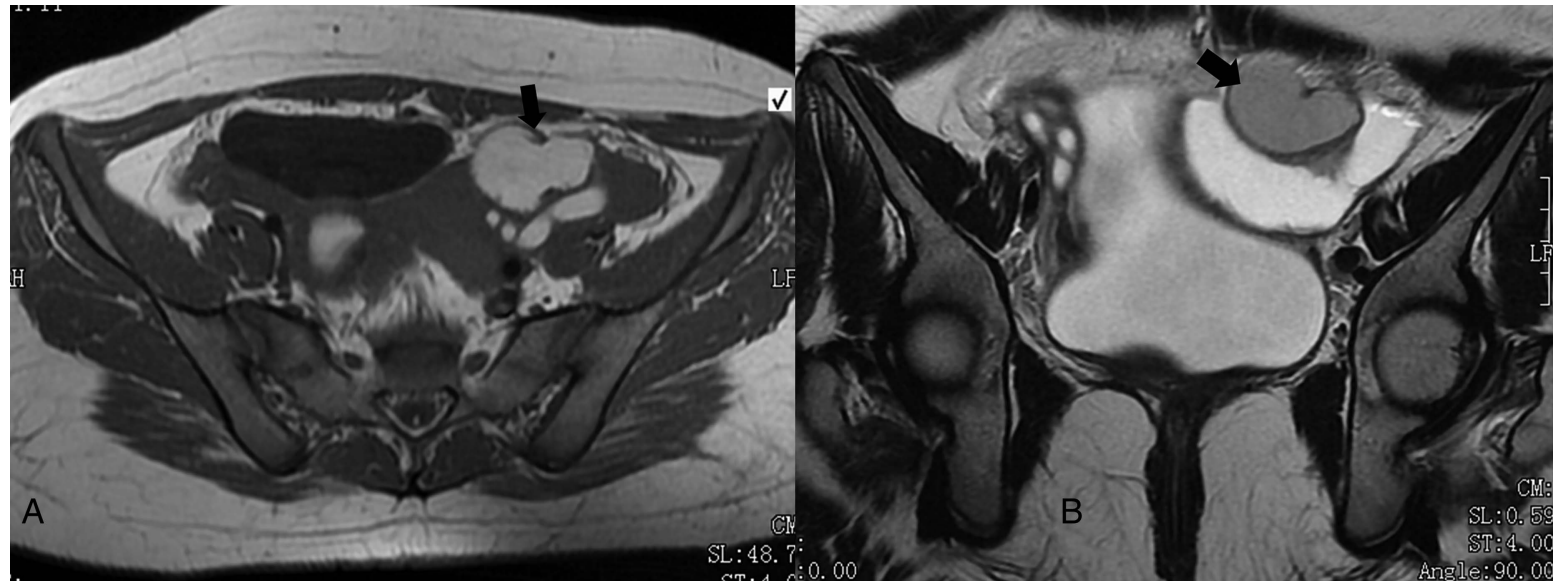

Figure 3 (A) Axial T1-weighted (T1W) image showing tortuous left fallopian tube distended with haemorrhagic fluid (bright on T1), suggesting haematosalpinx formation. Cystic dilation of the ampullary end (black arrow) is seen. (B) Coronal T2W image showing loculated fluid around the left-dilated fallopian tube (black arrow) indenting the dome of the urinary bladder.

suggesting haematosalpinx (figure 3). The right endometrial cavity was normally communicating with the cervical canal. Uterine fundus contour was normal (figure 1). Loculated fluid collection was seen around the left ovary as well as a dilated fallopian tube with no haemorrhagic products within (figure 3). Both ovaries were normal in size with multiple follicles. The right fallopian tube was normal. With these findings, a diagnosis of Robert's uterus was made. Hysteroscopy was performed, but the scope could not be advanced beyond the cervix due to stenosis. The patient underwent laparotomy with evacuation of haematometra, excision of the septum and left cervicovaginostomy. The loculated collection around the left ovary was a serous collection. There were no features of endometriosis in our patient.

Robert's uterus is a rare type of MDA and a variant of septate uterus (class V, American Society for Reproductive Medicine Classification), with very few cases of this variant being reported. It is also known as asymmetric septate uterus and was first reported by Robert in $1970 .{ }^{1}$ This condition is characterised by uterine septum dividing the endometrial cavity asymmetrically with non-communicating hemiuterus due to obstruction by the septum. As a result there is obstruction to menstrual flow in one cavity, resulting in haematometra, haematosalpinx and sometimes endometriosis. Patients present with recurrent abdominal pain and severe dysmenorrhoea. They can also present with acute pain of the abdomen as an emergency. ${ }^{1}$

Three-dimensional ultrasound is useful in the evaluation of patients with suspected MDAs. However, significant limitations remain in diagnosing MDA subtypes on ultrasound. ${ }^{2} \mathrm{MRI}$ is the preferred method of imaging as it is capable of showing the endometrial cavity and uterine contour in exquisite detail, and it has shown excellent agreement with clinical MDA subtype diagnosis. ${ }^{2}$ In cases of Robert's uterus the coronal T2W images of MRI are ideal for demonstrating the uterine septum dividing the endometrial cavity asymmetrically along with the blind ending cavity and haematometra. T1W images show the haematometra and haematosalpinx as bright fluid in the endometrial cavity and dilated fallopian tube. A rare complication of Robert's uterus is pregnancy in the non-communicating half of the uterus caused by transperitoneal migration of sperms. ${ }^{3}$
On laparoscopy or laparotomy the uterus shows normal fundal contour. Excision of the septum with unification of the endometrial cavity is usually performed. Endometriotic cysts, if present, are drained and excised. ${ }^{1}$ Early and accurate diagnosis of this condition using MRI is important in guiding towards appropriate surgical intervention.

\section{Learning points}

- Robert's uterus is also known as asymmetric septate uterus and is a rare congenital müllerian duct anomaly.

- $\mathrm{MRI}$ is the best modality to demonstrate the uterine septum, normal external fundal contour, haematometra and haematosalpinx.

- Early and accurate diagnosis of this condition is important in guiding towards appropriate surgical intervention.

Acknowledgements The authors would like to thank Dr Sundeep P T, Associate Professor, Department of Paediatric Surgery, KMC Manipal, for his inputs on the surgical management of Robert's uterus.

Contributors SBM was involved in conception and design. LHK and SK were involved in revising the article. SBM and KP approved the final version of the manuscript.

Competing interests None.

Patient consent Obtained.

Provenance and peer review Not commissioned; externally peer reviewed.

\section{REFERENCES}

1 Gupta N, Mittal S, Dadhwal V, et al. A unique congenital mullerian anomaly: Robert's uterus. Arch Gynecol Obstet 2007;276:641-3.

2 Behr SC, Courtier JL, Qayyum A. Imaging of müllerian duct anomalies. Radiographics 2012;32:E233-50.

3 Chandra M, Pathak V. Pregnancy in non-communicating half of septate uterus. J Obstet Gynaecol India 2012;62(Suppl 1):31. 
Copyright 2014 BMJ Publishing Group. All rights reserved. For permission to reuse any of this content visit http://group.bmj.com/group/rights-licensing/permissions.

BMJ Case Report Fellows may re-use this article for personal use and teaching without any further permission.

Become a Fellow of BMJ Case Reports today and you can:

- Submit as many cases as you like

- Enjoy fast sympathetic peer review and rapid publication of accepted articles

- Access all the published articles

- Re-use any of the published material for personal use and teaching without further permission

For information on Institutional Fellowships contact consortiasales@bmjgroup.com

Visit casereports.bmj.com for more articles like this and to become a Fellow 